\title{
A EVOLUÇÃO CIENTÍFICA E TECNOLÓGICA FRENTE ÀS ATUAIS ESTRATÉGIAS DE EMANCIPAÇÃO SOCIAL E COLETIVA PROPOSTAS PELO MOVIMENTO DE ECONOMIA SOLIDÁRIA: BASES EPISTEMOLÓGICAS PARA UMA DEVIDA E NECESSÁRIA APROXIMAÇÃO DO TEMA
}

\author{
Maria Inês Ferreira Marques ${ }^{1}$ \\ Maristela Miranda Vieira de Oliveira ${ }^{2}$
}

\begin{abstract}
RESUMO
Este artigo propõe uma reflexão crítica sobre o necessário diálogo entre a evolução científica e tecnológica presenciada nos últimos 30 anos e as atuais estratégias de fortalecimento do Movimento de Economia Solidária, a partir dos empreendimentos populares e dos seus agentes de desenvolvimento, tais como as Incubadoras Universitárias. Para tanto, a análise busca confrontar a fragilidade cognitiva observada em empreendimentos populares vinculados ao Movimento de Economia Solidária, com o advento das novas tecnologias no campo das Ciências Cognitivas. Devido à abrangência do tema em questão, bem como de sua problemática, definem-se como objeto de estudo as teorias e conceitos que servem de base epistemológica para a Economia Solidária, tais como Singer (2002), Dagnino (2002), França Filho e Laville (2004), bem como aquelas que participam do advento do campo das Ciências Cognitivas e suas vertentes, a saber, F. Lyotard (2000), Davenport e Prusak (1998), Nonaka e Takeuchi (1997), dentre outros. Como resultado dessa reflexão, entende-se que o campo das Ciências Cognitivas e suas demais vertentes têm muito a contribuir com os empreendimentos da Economia Solidária, uma vez que desenvolvem tecnologias de apoio às Organizações e que, atualmente, vêm sendo apoderadas pela economia de mercado como forte diferencial competitivo.
\end{abstract}

Palavras-chave: Economia Solidária. Ciência e Tecnologia. Estratégias Cognitivas.

THE SCIENTIFIC AND TECHNOLOGICAL DEVELOPMENT OF THE CURRENT
STRATEGIES OF SOCIAL AND COLLECTIVE EMANCIPATION PROPOSED BY THE
MOVEMENT OF SOLIDARITY ECONOMY: EPISTEMOLOGICAL
BASES FOR A NECESSARY APPROXIMATION OF THE THEME

\begin{abstract}
This article proposes a critical reflection on the necessary dialogue between the scientific and technological evolution witnessed in the last 30 years and the current strategies to strengthen the Solidarity Economy Movement, starting from the popular enterprises and their development agents such as the Incubators University students. To do so, the analysis seeks to confront the cognitive fragility observed in popular enterprises linked to the Solidarity Economy Movement, with the advent of new technologies in the field of Cognitive Sciences. Due to the scope of the theme in question, as well as its problematic, the theories and concepts that serve as the epistemological basis for the Solidarity Economy, such as Singer (2002), Dagnino (2002), França Filho and Laville (2004) as well as those who participate in the advent of the field of Cognitive Sciences and its aspects, namely F. Lyotard (2000), Davenport and Prusak (1998), Nonaka and Takeuchi (1997). As result of this reflection it is understood that the field of Cognitive Sciences and its other aspects has much to contribute with the enterprises of the Solidary Economy since they develop technologies of support to the Organizations and that, at the moment, has been taken over by the market economy as strong competitive differential.
\end{abstract}

Keywords: Solidary Economy. Science and Technology. Cognitive Strategies

\footnotetext{
${ }^{1}$ Doutora em Educação pela Universidade Federal da Bahia (UFBA), docente do Programa de Doutorado Multidisciplinar e Multi Institucional em Difusão do Conhecimento (UFBA).E-mail: br3imarques@yahoo.com.br

2 Doutoranda do Programa Multidisciplinar e Multi Institucional em Difusão do Conhecimento. Docente do Departamento de Ciências Sociais Aplicadas (DCSA/UESB). E-mail: maristelamvo@gmail.com
} 


\section{Introdução}

Há aproximadamente 20 anos, o Movimento de Economia Solidária se faz presente nas esferas rural e urbana, atuando na produção e comercialização de produtos que são resultado de um esforço coletivo das diversas associações e cooperativas que compartilham dos seus princípios.

Em relação ao conceito, este Movimento costuma ser entendido a partir da concepção de um modo de produção, estando vinculado a uma estratégia diferenciada que considere a cooperação, a solidariedade, a criação de redes, a gestão do conhecimento e a autogestão como forma de desenvolver uma prática de produção e comercialização que possibilite oportunidade a todos, principalmente àqueles que se encontram à margem do atual sistema (SINGER, 2002; GAIGER, 2004; FRANÇA FILHO, 2002; ARRUDA, 2007; CORAGGIO, 2007; KRAYCHETE; AGUIAR, 2007).

Para Dagnino (2002), a Economia Solidária se tornou mais que um Movimento, ou uma estratégia, ela se transformou em uma espécie de setor da economia na medida em que a economia formal, em países periféricos, não é capaz de absorver todo o contingente de pessoas em busca de geração de renda, fazendo crescer a cada dia o número de desempregados e excluídos do sistema. A Economia Solidária, através de uma estratégia que dialoga com mercado e sociedade sem fortalecer valores excludentes e competitivos, cria a oportunidade de desenvolvimento desses profissionais, atuando pontualmente na geração de trabalho e renda e contribuindo para o desenvolvimento de cidades e regiões.

Contudo, o desenvolvimento desse Movimento está pautado em três pilares fundamentais, conforme aponta Dagnino (2002): o material, o político e o cognitivo. Considerando o apoio governamental que o Movimento recebeu nas últimas duas décadas, com subsídios e editais públicos, bem como o crescimento do espaço político resultado da criação da Secretaria Nacional dentro do Ministério do Trabalho, conselhos e coordenações municipais, resta o fortalecimento do aspecto cognitivo como forma de garantir a sua sustentabilidade.

Nesse sentido, preocupa a condição de desenvolvimento tecnológico que vem ficando aquém dos esforços materiais e políticos, uma vez que, para se posicionar num mercado excludente e competitivo, é preciso se apoderar do arcabouço científico e tecnológico utilizado por este mercado. Só nesse contexto os empreendimentos solidários podem se defender, dando sustentabilidade ao seu negócio e fortalecendo a sua estratégia.

Em aproximadamente 20 anos de existência, é possível reunir aspectos observáveis entre as diversas cooperativas e associações partícipes do Movimento que sugerem a ausência de estratégias cognitivas capazes de contribuir para a autonomia dos empreendimentos, tais como:

- ausência de instrumentos e estratégias reais para viabilizar articulação em rede: nesse âmbito, conta-se hoje com o Mapeamento da Economia Solidária, o Sistema Nacional de Informações de Economia Solidária e o Observatório de Economia Solidária, tais ferramentas existem no âmbito de 
governo e reúnem informações que caracterizam os empreendimentos, tornando-se uma ferramenta de dados primários possível de criar indicadores. A necessidade de articulação em rede é fator prioritário para o fortalecimento do Movimento e deve levar em conta a extensão quase continental do país, com todas as suas especificidades entre as diversas regiões. A articulação em rede aponta para a possibilidade de criar canais de distribuição dos produtos da Economia Solidária, além de ser identificador e multiplicador de soluções encontradas nas diversas situações, em diversos ambientes, capaz de contribuir para a resolução de desafios in loco. Hoje, esse encontro de práticas com discussão e diálogo entre diversos empreendimentos costuma acontecer em espaços de eventos, seminários, congressos, ou mesmo através de sites independentes de incubadoras e empreendimentos. Também é possível conhecer diversas realidades através de pesquisas monográficas, dissertações e teses, todas de caráter particular, desenvolvidas a partir de um interesse individual. Não se verifica, entretanto, uma possibilidade de levantamento desses dados com articulação para fazer chegar aos principais interessados todas as descobertas, possibilidades e soluções encontradas por seus pares no âmbito de país, ainda que as realidades sejam específicas a cada região.

- ausência de desenvolvimento de instrumentos de gestão configurados para a realidade do Movimento com seus valores, princípios, rotinas e estratégias próprias: é comum a utilização de estratégias desenhadas para a realidade das empresas privadas, principalmente entre Incubadoras Universitárias que utilizam-se, muitas vezes, de todo um arcabouço teórico advindo dos manuais de Administração, nos quais, sabe-se, também é algo novo o olhar para as Organizações Sociais e do Terceiro Setor. Nesse ínterim, é possível listar instrumentos como cálculos de formação de preços, relatórios contábeis, elaboração de Planejamentos Estratégicos, instrumentos para mensuração de comportamento organizacional, gestão de RH, psicologias organizacionais, estratégias de marketing, softwares de gestão, dentre tantas outras ferramentas de apoio à gestão que foram elaboradas a partir da razão de competição, concorrência e exclusão advindas do atual sistema de produção.

- ausência de confrontação de metodologias de incubação a fim de desenvolver método específico para a realidade dos empreendimentos solidários: o acompanhamento de incubadoras e a captação de recursos costumam ser feitos através de editais públicos. Contudo a exposição dos resultados inerentes a estas intervenções limitam-se a eventos e relatórios de prestação de contas sem, contudo, evoluírem para a construção do conhecimento baseado nas experiências e com disponibilização de tais dados em rede para fins de pesquisas e futuros processos de tomada de decisão.

- ausência de cursos técnicos ou disciplinas específicas em cursos superiores, capazes de atuar na formação de profissionais dentro do Movimento, bem como intercâmbios, premiações e troca das melhores práticas. 
É preciso atentar para o fato de que a transformação perseguida pelos empreendimentos autogestionários que precisam e devem buscar o seu fortalecimento e desenvolvimento deve acontecer dentro do contexto que lhe cerca, dialogando com as diferenças, dialogando com a realidade presente, inserindo-se no tripé Ciência, Tecnologia e Sociedade sem, para tanto, se perder diante dos princípios e valores que lhe sustentam.

Urge sair em busca da apreensão cognitiva necessária para dialogar com a ciência e tecnologia de forma a desenvolver ferramentas e estratégias adequadas à sua realidade. Para tanto, é preciso se apoderar do discurso, conceitos e instrumentos que servem à economia de mercado, desenvolvendo novas ferramentas que deem sustentabilidade ao Movimento, fortalecimento das redes, fortalecimento da comunicação estratégica e desenvolvimento de novas tecnologias. São esses os fatores que definem a competição num mercado hegemônico e são essas as armas que agentes de desenvolvimento como as Incubadoras Universitárias devem dominar a fim de transferir essa tecnologia para os empreendimentos, fortalecendo-os.

\section{Aspectos Metodológicos}

O presente artigo se desenvolve a partir do questionamento: como a evolução científica e tecnológica pode contribuir para o fortalecimento e sustentabilidade dos empreendimentos de Economia Solidária? A discussão que se processa a partir de tal questionamento pode vir a confrontar os princípios de uma economia que se deseja plural (na qual estejam conciliados mercado, sociedade e governo) com a economia de mercado, na qual as novas tecnologias se fazem presentes para fins de competição e reserva de mercado.

Olhar a ciência e a tecnologia como aporte necessário para uma sustentabilidade econômica impõe realizar o diálogo entre bases epistemológicas diferenciadas, vez que o desenvolvimento tecnológico está muito mais direcionado ao modo de produção hegemônico do que à perspectiva de um novo modo de produção, como pretende a Economia Solidária.

Nesse sentido, a discussão que ora se inicia propõe uma busca teórica dessas bases epistemológicas a fim de criar o ambiente necessário ao diálogo proposto. Para tanto, optou-se por realizar uma breve retomada histórica daqueles que foram pioneiros da ideia de organizações autogestionárias, apontandose muitos pensadores das Escolas Inglesa e Francesa não socialistas e também liberais, que comungavam da ideia de cooperativas e associações. Em seguida, apresentam-se os atuais estudiosos da Economia Solidária, sendo esta uma evolução do Movimento Cooperativista e da Economia Social, bem como as preocupações em relação à sustentabilidade dos empreendimentos autogestionários. Para realizar o encontro pretendido, cumpre então apresentar autores que compõem o advento do campo das ciências cognitivas que, por sua vez servem de base para o desenvolvimento de novas tecnologias e as diversas possibilidades que esse ambiente oferece para as organizações modernas. 
A importância de revisitar as bases teóricas que servem de fundamento para o que existe hoje em termos de empreendimentos autogestionários e tecnologia está na possibilidade de buscar um diálogo equilibrado, sem colocar em risco os princípios e valores que sustentam a Economia Solidária.

\section{Bases históricas da Economia Solidária}

O caminho que leva à construção da ideia de uma Economia Solidária passa, necessariamente, pelo surgimento dos primeiros empreendimentos associativistas e cooperativistas. Tais empreendimentos já existiam, em forma de cooperativas de consumo, desde o século XVIII e remontam ao surgimento da Revolução Industrial, momento em que se inaugurava um período de novas perspectivas econômicas e industriais, potencializando as injustiças sociais, exclusão, enriquecimento dos proprietários dos meios de produção, em detrimento de grande empobrecimento dos proprietários da força produtiva.

O ideal cooperativista, portanto, nasceu impulsionado pelos rumos traçados pelo sistema capitalista, tendo sido praticado, principalmente, por aqueles que vivenciavam a exploração da mão de obra e sentiam-se condenados a viver à margem de um sistema no qual o trabalho tornara-se meio, em detrimento do lucro, maior multiplicador do capital.

Nesse sentido, Singer, enquanto pesquisador da Economia Solidária, entendendo-a como forma de superação dos desafios impostos à população excluída do atual modo de produção, apontou o sistema capitalista como o principal responsável pela extrema desigualdade da sociedade contemporânea, afirmando que:

O capitalismo produz desigualdades crescentes, verdadeira polarização entre ganhadores e perdedores. Enquanto os primeiros acumulam capital, galgam posições e avançam nas carreiras, os últimos acumulam dívidas pelas quais devem pagar juros cada vez maiores, são despedidos ou ficam desempregados até que se tornam inempregáveis, o que significa que as derrotas os marcaram tanto que ninguém mais quer empregá-los (SINGER, 2002, p. 8).

Portanto, o surgimento das cooperativas representou uma alternativa de sobrevivência daqueles que, sozinhos, não passavam de unidades de exploração, passíveis de manipulação em prol do fortalecimento de um sistema altamente excludente.

A união da força de trabalho e da solidariedade, somado ao resgate da dignidade humana e da luta pela sobrevivência, tornou-se uma forma alternativa de produção em uma economia baseada estritamente nas leis de mercado, além de uma forma de proteção quanto à ação devastadora da busca pelo lucro.

Cabe lembrar que, no contexto histórico vivido pela Europa do século XIX, e que desencadeou todo o movimento cooperativista, iniciou-se um Movimento conhecido por Economia Social que estava ligada ao direito ao trabalho, representando alternativa ao sistema produtivo capitalista que se tornava hegemônico naquele momento. Nesse contexto, surgiram várias escolas de pensamento que discutiram 
formas diferenciadas de se pensar a economia e o desenvolvimento do cooperativismo. Com diferentes vertentes na França e Inglaterra, dividiram-se entre:

\section{Escola radicalmente social - Socialistas Utópicos:}

- Marcel Mauss: francês, sociólogo e considerado o pai da antropologia na França (1872-1950).

- Benoit Malon: francês, militante socialista, dirigente da Comuna de Paris (1841-1893).

- Robert Owen: galês, considerado o Pai do Cooperativismo (1771-1858).

- Willian King: inglês, publicou a revista “The cooperador" (1786-1865).

- Charles Fourier: francês, socialista, idealizou colônias autossustentáveis "Falanges" (1772-1837)

- Philippe Buchez: francês, político, historiador e sociólogo (1796-1865).

- Louis Blanc: espanhol, crítico da livre concorrência, considerado precursor do socialismo estatal (1811-1882).

\section{Escola Social - cristã reformista:}

- Fréderic Le Play: francês, economista, entendia o cooperativismo a partir de um sentido reformista e não de transformação radical da sociedade (1806-1882).

\section{Escola Liberal:}

- Charles Dunoyer: francês, economista (1786-1862).

- Fréderic Passy: francês, fundador da Sociedade Francesa para a Paz, defendia a liberdade da economia e afastamento da intervenção do Estado (1822-1912).

- Leon Walras: francês, economista e matemático, defensor das associações populares (1834-1910).

- John Stuart Mill: inglês, filósofo e economista, defendia a superação do proletariado através das associações de trabalhadores (1806-1873).

\section{Escola Solidária:}

- Auguste Ott: francês, economista, filósofo e jornalista, enfatizava a independência das cooperativas dos partidos políticos e das igrejas e defendia as cooperativas de consumo como o centro de uma transformação social (1814-1892).

- Charles Gide: francês, líder histórico do movimento cooperativista francês, enunciava as 12 virtudes do cooperativismo (1847-1932).

A Economia Social dividiu-se em duas vertentes, uma que se voltou para a economia não mercantil, caracterizada pelo mutualismo, com uma proposta de total submissão ao poder público; e outra que se voltou para a economia mercantil, que responde às regras do mercado, ocupando lacunas onde o sistema capitalista permanecia fraco, sendo, portanto, representado pelo cooperativismo.

Nesse sentido, a Economia Solidária deve ser entendida como uma evolução da Economia Social e do Movimento Cooperativista do século XVIII, ou seja, apesar de compartilhar o contexto histórico nascente em relação ao cooperativismo e associativismo, e que representou o advento da Economia Social, não pode ter a mesma definição, pois a sua proposta está além dessas vertentes, conforme sugere França Filho (2002, p. 13): 
É justamente em relação às características atuais assumidas pela Economia Social que vem se demarcar a noção de Economia Solidária, pela afirmação da dimensão política na sua ação. O que nos leva a defini-las como experiências que se apoiam sobre o desenvolvimento de atividades econômicas para a realização de objetivos sociais, concorrendo ainda para a afirmação de ideais de cidadania.

Logo, a Economia Solidária pretende uma nova forma de relacionamento, não se sustentando somente nas relações com a economia ou com o Estado, mas acima de tudo exige um olhar para as relações tecidas entre a economia, o Estado e a sociedade.

Hoje, a evolução da ideia cooperativista, unida às demais formas associativas, bem como às ações de caráter social e solidário, convergem para a formação da Economia Solidária, em que se verificam não só as cooperativas populares, mas também outras associações como clubes de troca, bancos do povo, feiras de artesanato, redes de projetos comunitários, instâncias governamentais, entidades de apoio e fomento e demais instituições baseadas na solidariedade e cooperação.

\section{Desafios contemporâneos da Economia Solidária: a fragilidade cognitiva como fator limitante}

França Filho e Laville (2004) observam que as sociedades tradicionais priorizavam a manutenção dos vínculos sociais em relação à produção de riquezas, tornando a economia imbricada nas relações sociais. Porém, na atualidade, presencia-se uma legitimação da economia de mercado mediante a busca da satisfação dos interesses individuais.

A atual concepção de economia de mercado cria uma dissociação entre o plano econômico e o social, o que elimina o debate político das questões econômicas. Contudo, a Economia Solidária preza por um mercado pautado na Economia Social, criando relações que "examinam as condições, permitindo conciliar o modo de produção econômico com uma redução da pobreza que ameaça a ordem estabelecida" (FRANÇA FILHO; LAVILLE, 2004, p. 50).

A Economia Solidária, portanto, sinaliza para uma articulação entre a economia mercantil (mercado), não mercantil (governo) e não monetária (dádiva), convergindo para a solidariedade que será o centro de uma relação pautada em objetivos de natureza social, política e cultural (FRANÇA FILHO; LAVILLE, 2004).

Essa articulação abre caminho para o desenvolvimento da proposta de uma economia plural, contudo, como ainda se mostra uma prática em construção, convive com lacunas que se tornam urgentes diante do esforço de fortalecimento do Movimento e da necessidade de conquistar o seu espaço, como por exemplo, a questão das tecnologias de apoio aos empreendimentos.

Nesse sentido, Dagnino (2002) afirma a necessidade crescente da utilização das evoluções científica e tecnológica nos novos caminhos de desenvolvimento da Economia Solidária, como forma de gerar a sua sustentabilidade diante do dinamismo do mercado hegemônico que a circunda. 
Singer também é defensor desse pensamento; para o autor, a Economia Solidária não quer nem pode acolher todos as pessoas, esvaziando a economia formal, não é essa a intenção. Na verdade, a estratégia da nova forma de se fazer a economia é lidar com um grupo de profissionais e conquistar um espaço de desenvolvimento que possa estar conciliado com a economia de mercado, ou formal, como se queira colocar.

A Economia Solidária, por todo o seu histórico e raízes, nasceu para acolher excluídos de um sistema produtivo, garantindo-lhes meios de sobrevivência num mercado altamente individualista. O desenvolvimento desta estratégia presume uma convivência articulada com esse mercado, de forma a garantir um espaço produtivo e de distribuição, capaz de gerar condições de liberdade e qualidade de vida baseadas na solidariedade e compromisso com valores éticos e morais muitas vezes inexistentes no mercado formal. Porém, para que seja possível essa realidade, a Economia Solidária deverá transitar na economia formal, mantendo as suas regras e convivendo com as regras daquela. Isso é possível desde que observadas as suas condições de fortalecimento. E, neste quesito, Dagnino (2002) chama a atenção para três fatores que se fazem essenciais em uma política pública que se queria exequível: os fatores materiais, políticos e cognitivos.

No caso da Economia Solidária, tendo a mesma recebido apoio de governos ao longo de, aproximadamente, duas décadas, no Brasil, é visível o apoio material e político, vez que o Movimento já consegue contemplar uma maturidade política e criação de Instituições de apoio como os Conselhos Municipais. Contudo, os fatores cognitivos tornam-se desafios a serem superados na medida em que o Movimento cresce, se expande e passa a carecer de estratégias de sustentabilidade como requisito para se manter em diálogo com a economia de mercado. Para tanto, vinte anos de história já postulam condições suficientes de visualização dos desafios numa forma de produção que vem ganhando espaço e com práticas espalhadas por dentro e fora do país.

\section{O campo das ciências cognitivas como ambiente necessário de trânsito da Economia Solidária: autores e referências para uma aproximação do tema}

As ciências cognitivas surgem historicamente no pós-guerra, inaugurando o pensamento pósmoderno e concomitante ao enfraquecimento do pensamento estruturalista. Nasce como um paradigma provindo do encontro de ciências como a Psicologia, Antropologia, Biologia, Neurologia, Mecânica Quântica, Termodinâmica, Cibernética, Ciência da Informação, e desencadeia em diversas novas disciplinas como a Inteligência Artificial, a Neurociência, Teoria dos Autômatos, Engenharia do Conhecimento, Modelagem do Conhecimento, Robótica, dentre tantas novas áreas que buscam ganhar acesso aos fenômenos mentais, unindo-os a fatos socioculturais.

Traz em sua raiz histórica a evolução da Linguística e o pensamento de diversos teóricos que lançaram as primeiras contribuições ao cognitivismo, tais como: 


\section{Precursores das Ciências Cognitivas:}

- Noam Chomsky com estudos profundos da Linguística traduzido em regras formais como na matemática.

- Alan Turing, que desenvolveu uma máquina para executar cálculos complexos.

- Warren McCulloch e Walter Pitts, que demonstraram ser possível modelar em termos de lógica uma célula nervosa e suas conexões.

- Claude Shannon demonstrando que circuitos elétricos poderiam conter operações fundamentais do pensamento.

- Humberto Maturana, criador do conceito de Autopoiese, defendendo que todos os organismos vivos funcionam devido à sua interação com o meio, gerando uma mudança estrutural contínua.

Além de autores como Dan Sperber, que entende a Ciência Cognitiva como uma pretensão de ampliar o domínio das ciências naturais em direção às ciências sociais, reduzindo as fronteiras que opõem a ciência do homem às da natureza e que foi o caminho trilhado por muito tempo no campo científico. Edgar Morin com o estudo da complexidade, Howard Gardner com a teoria das sete dimensões da inteligência, dentre muitos outros teóricos que se dedicaram a uma nova reflexão sobre o sujeito e o estudo do conhecimento a partir de uma perspectiva mista entre seres humanos e máquinas.

Enquanto novo campo de pesquisa, a Ciência Cognitiva busca uma abordagem transdisciplinar da complexidade, criando um diálogo entre o natural e o social, inaugurando um pensamento paradoxal num contexto científico até então dominado pelo pensamento binário (DOSSE, 1994).

A partir desse descortinar da Pós Modernidade, várias tecnologias foram e são criadas tendo como fundamento maior os aspectos cognitivos atrelados ao desenvolvimento de softwares, jogos, máquinas inteligentes, circuitos, redes complexas, ambientes de aprendizagem, simuladores, dentre tantas inovações que estão hoje à serviço da sociedade e, principalmente, a serviço do capital.

Para J. F. Lyotard (2000), o advento da Pós-Modernidade inaugura uma era Pós-Industrial, tendo o conhecimento se tornado a principal força econômica e de produção. Nesse sentido, entende que o contexto atual não mais admite visões totalizantes da História, criticando metanarrativas como socialismo, comunismo, marxismo e apontando para a necessidade de um caminho possível onde Ciência e Sociedade possam dialogar, ou seja, "bom é o saber que produz os melhores resultados" (LYOTARD, 2000). Dessa forma, aponta para a necessidade do reconhecimento e diálogo com as diferenças, ao que deu o nome de parologia, o bom saber deve ser identificado a partir do estudo das "regras" que lhe deram origem e essas regras implícitas devem ser questionadas localmente, originando novos conceitos.

É a partir dessa visão entre Ciência, Tecnologia e Sociedade que se configura o necessário diálogo entre as iniciativas econômicas solidárias, no que tange ao seu objetivo de transformação social e coletiva, e as novas tecnologias disponíveis para gestão do conhecimento. É preciso compreender as armas utilizadas no mercado competitivo e participar de sua criação, transformando-as em instrumento 
de apoio e fortalecimento dentro da realidade que o ambiente apresenta. E, como existe toda uma ressignificação de valores que alimentam tais empreendimentos, necessário se faz o esforço em dialogar com temas que possam agregar valor às estratégias de fortalecimento do Movimento de Economia Solidária dentro do campo cognitivo, reconfigurando as "regras" de desenvolvimento das tecnologias que lhe são de interesse a fim de poder socializar este conhecimento.

Entre tantas novas áreas de desenvolvimento de tecnologias, pode-se citar, por exemplo, a Gestão do Conhecimento, área de estudo que acompanha a evolução da Teoria Organizacional e que rege a forma como se gerencia o conhecimento corporativo. Conforme defendem Davenport e Prusak (1998), “a única vantagem sustentável que uma Organização possui é aquilo que ela coletivamente sabe, a eficiência com que usa o que sabe e a prontidão com que adquire novos conhecimentos". A Gestão do Conhecimento atua numa perspectiva de complexidade e multidimensionalidade, elevando o seu olhar para o ambiente econômico e social, a evolução tecnológica, as estratégias organizacionais, as estruturas hierárquicas, as tarefas e trabalhos em grupo e a cognição humana.

Ainda transitando pela Gestão do Conhecimento, observam-se as teorias de Nonaka e Takeuchi (1997), quando discutem o desafio da criação do conhecimento a partir de dois paradigmas: o ontológico, em que defendem que o conhecimento é criado apenas por indivíduos num processo interno a uma comunidade, na interação entre os pares, e que se expande para além da Organização. E o epistemológico, no qual os autores criam uma discussão sobre o conhecimento tácito e explícito, inferindo que o primeiro é algo pessoal e específico ao contexto, sendo mais difícil de ser formulado e comunicado. Já o conhecimento explícito refere-se ao conhecimento transmissível, codificado em linguagem formal e sistemática.

No âmbito da Economia Solidária, o fazer diário com grupos populares preconiza uma atuação cuidadosa que envolve aspectos culturais em confronto com aspectos organizacionais. Nesse sentido, é comum o confronto entre o conhecimento tácito e o explícito a partir das equipes que formam a base de apoio aos empreendimentos, tais como as Incubadoras Universitárias. Nessa relação, a Academia transfere o conhecimento articulado na linguagem formal e, portanto, apresentado a partir de manuais, técnicas e metodologias e, por sua vez, se depara com o conhecimento informal, pessoal e incorporado à experiência individual, envolvendo fatores intangíveis, como crenças e sistemas de valor. A forma como acontecerá o diálogo a partir dessas duas dimensões definirá o sucesso ou não do empreendimento que se deseja montar.

Logo, as Incubadoras Universitárias atuam através de metodologias que focalizam procedimentos relacionados à transferência e construção do conhecimento e que devem estar pautados em uma abordagem multidisciplinar, transdisciplinar, multidimensional e multirreferencial, garantindo que tais concepções de aprendizagem englobem ações, conhecimentos e afetos, permitindo a construção de uma relação de segurança e cumplicidade entre o grupo e os profissionais, além de buscar distinguir seus atores dentro de uma perspectiva de diálogo a partir de diversos referenciais, criando, assim, um ambiente propício para a busca dos resultados almejados. 
Esses resultados, ou metas, estão diretamente vinculados à perspectiva da gestão do conhecimento, vez que se trata de projetos sociais com vistas à criação de um ambiente organizacional. Isso significa que a Incubadora Universitária possui como desafio relacionar e aproveitar todo o conhecimento tácito do grupo para gerar valor ao conhecimento explícito, criando, assim, uma estrutura capaz de dar sustentabilidade ao empreendimento nascente. Tudo isso numa perspectiva de emancipação social e coletiva, sem perder de vista o caráter humano das relações ali construídas e, principalmente, transformando cada indivíduo em ator desse processo.

No campo da Inteligência Artificial, é possível também acrescentar nessa discussão a área de Modelagem do Conhecimento, que busca a elaboração de modelos formais, permitindo a apropriação do saber por toda uma rede. Este conceito parte da Engenharia do Conhecimento e tem como principal expoente Allen Newell (1927-1992), pesquisador da Ciência da Computação e psicólogo cognitivo, foi o idealizador dos primeiros programas de Inteligência Artificial, contribuindo na linguagem do processamento de informação. Também se tornou conhecido por sua Teoria da Cognição, na qual defendia que o problema científico escolhe o pesquisador e não o contrário.

Logo, a Modelagem do Conhecimento é um desdobramento da Engenharia do Conhecimento que, por sua vez, nasce do desenvolvimento da Inteligência Artificial. Busca o desenvolvimento de ambientes computacionais capazes de automatizar fases da interpretação de imagens, símbolos, informações, em um ambiente integrado. A ideia é a de que os Modelos não precisam inspirar-se em modelos humanos, desde que consigam reproduzir o seu comportamento. Neste contexto, não se pode transitar sem entender os princípios da teoria dos sistemas, complexidade e caos, redes complexas, redes semânticas, dentre outros.

Os Sistemas Complexos tornam-se, portanto, parte importante desse encontro, no sentido de que possibilitará sustentar toda a discussão sobre transformação de dados em informações e dessas em conhecimento visando à transformação e/ou evolução de estratégias já utilizadas no âmbito do Movimento em questão. Para tanto, e consoante à visão de vários autores da área, entende-se que Sistemas Complexos pressupõem sistemas dinâmicos, não lineares, que contêm grande número de interações entre as partes. Esses sistemas se modificam, de modo a aprenderem, evoluírem e adaptarem-se e geram comportamentos emergentes e não determinísticos. Os sistemas complexos se adaptam e interagem com os seus vizinhos por conexões de Redes (FURTADO; SAKOWSKI; TÓVOLLI, 2015).

A ideia de Redes está presente na Economia Solidária desde o seu nascimento como forma de sustentação do Movimento. Atuar em redes é ponto crucial para a integração dos empreendimentos e já tem se mostrado um desafio a ser superado na medida em que se observa um grande avanço territorial dentro e fora do Brasil, reunindo empreendimentos dos mais diversos setores, do campo e da cidade, com estratégias diferenciadas que precisam dialogar entre si e promover a troca de experiências e a difusão do conhecimento existente entre os seus elos. 
E, para finalizar, sem a pretensão de querer esgotar o tema em questão, uma vez que este ensaio busca apenas a devida aproximação de uma discussão que tem sido pouco tratada no âmbito da Economia Solidária, cabe ressaltar que todo esse aparato tecnológico que envolve conhecimento, ferramentas, modelos e teorias diversas, pode e deve ser analisado à luz dos Softwares Livres que tornaram-se realidade no final do século XX e prezam pelo respeito, liberdade e senso de comunidade dos usuários. Ora, nesse quesito não há nada mais parecido com o Movimento de Economia Solidária na sua característica de acolher ao invés de reprimir, cooperar ao invés de competir, respeitar e dialogar com as diferenças, numa estratégia de atuação em rede.

\section{Considerações Finais}

Este artigo teve como principal intenção propor uma reflexão crítica sobre a necessária aproximação da Economia Solidária com as evoluções no âmbito da ciência e tecnologia. Para tanto, a análise buscou confrontar a fragilidade cognitiva dos empreendimentos da Economia Solidária com o advento das novas tecnologias no campo das Ciências Cognitivas, que podem contribuir para o fortalecimento das estratégias de desenvolvimento do Movimento.

A partir da breve apresentação de teóricos que contribuíram para o Movimento Cooperativista do século XVIII, identificaram-se as bases epistemológicas que compõem a Economia Solidária, entendendo-a como um Movimento que nasce no final do século XIX com a intenção de proteger parcela da sociedade excluída do atual sistema de produção e que possui uma demanda que vai além dos interesses do Cooperativismo que era, estritamente, de ordem econômica, enquanto a Economia Solidária busca transitar entre a economia, política e mercado.

Nesse viés, observou-se que o Movimento de Economia Solidária tem conseguido abrir espaço na agenda política através do apoio que recebeu, nos últimos 20 anos, do Estado. Apoio este que também se traduziu em aspectos materiais quando da criação de políticas públicas para subsidiar a criação de empreendimentos econômicos solidários. Contudo, percebe-se uma lacuna no quesito cognitivo e esta é apontada por Dagnino (2002) como um dos pilares para a exequibilidade de uma boa política pública que representaria os fatores materiais, políticos e cognitivos.

Em se tratando de fatores cognitivos, a preocupação esbarra no desenvolvimento de tecnologias que possam contribuir para o fortalecimento do Movimento diante da sua atuação num mercado altamente competitivo, excludente e dinâmico. Presume-se que os empreendimentos econômicos solidários não estariam revestidos da tecnologia necessária para garantir seu diálogo com esse mercado.

Nesse viés, urgente se faz o diálogo com a ciência e tecnologia, no sentido de conhecer e se apoderar dos instrumentos estratégicos que servem às empresas da economia de mercado, sob pena de que os empreendimentos econômicos solidários não consigam evoluir da condição de economia periférica e também não consigam fazer bom uso dos outros fatores que determinam o seu potencial de participação na economia, quer seja o material e o político. 
No campo das Ciências Cognitivas, apresentam-se inúmeras possibilidades de desenvolvimento tecnológico que podem dialogar com as necessidades da Economia Solidária, a exemplo das tecnologias de Gestão do Conhecimento, Inteligência Artificial, Engenharia do Conhecimento, Modelagem do Conhecimento, Redes Complexas, Softwares Livres e todo o aparato tecnológico que hoje está em pleno desenvolvimento e serve à economia de mercado.

\section{Referências}

ARRUDA, M. Estratégia de formação no campo da economia dos setores populares. In: KRAYCHETE, Gabriel; AGUIAR, Kátia (Org.). Economia dos setores populares: sustentabilidade e estratégias de formação. São Leopoldo: Oikos, 2007.

CORAGGIO, J. L. Sustentabilidade e luta contra-hegemônica no campo da Economia Solidária. In: KRAYCHETE, Gabriel; AGUIAR, Kátia (Org.). Economia dos setores populares: sustentabilidade e estratégias de formação. São Leopoldo: Oikos, 2007.

DAGNINO, R. Em direção a uma estratégia para redução da pobreza: a economia solidária e a adequação sócio técnica. Organización de Estados Iberoamericanos (OEI), 2002. Disponível em:

<http://www.oei.es/historico/salactsi/rdagnino5.htm>. Acesso em: 12 nov. 2017.

DAVENPORT, Thomas H.; PRUSAK, Laurence. Conhecimento empresarial: como as empresas gerenciam o seu capital intelectual. Rio de Janeiro: Campus, 1998.

DOSSE, François. História do Estruturalismo: o canto do cisne de 1967 aos nossos dias. Campinas: Editora da Universidade Estadual de Campinas, 1994.

FRANÇA FILHO, G. C. A perspectiva da economia solidária. In: FISCHER, T. (Org.). Gestão do desenvolvimento e poderes locais: marcos teóricos e avaliação. Salvador: Casa da Qualidade, 2002.

; LAVILLE, Jean-Louis. Economia solidária: uma abordagem internacional. Porto Alegre: Editora da UFRGS, 2004.

FURTADO, B. A; SAKOWSKI, P. A. M.; TÓVOLLI, M. H. Modelagem de sistemas complexos para políticas públicas. Brasília: IPEA, 2015.

GAIGER, Luiz Inácio (Org.). Sentidos e experiências da economia solidária no Brasil. Porto Alegre: Editora da UFRGS, 2004.

KRAYCHETE, G.; AGUIAR, K. (Org.). Economia dos setores populares: sustentabilidade e estratégias de formação. São Leopoldo: Oikos, 2007.

LOMBARDI, José Claudinei (Org.). Globalização, pós-modernidade e educação. 2. ed. Campinas: Autores Associados; HISTEDBR, 2003.

LYOTARD, J. F. A condição pós-moderna. 6. ed. Rio de Janeiro: José Olympio, 2000.

METZ, Jean. Redes complexas: conceitos e aplicações. São Carlos: Instituto de Ciências, Matemática e de Computação, 2007.

MLADENATZ, G. História das doutrinas cooperativas. Brasília: Confebras, 2003. 
NONAKA, Ikujiro; TAKEUCHI, Hirotaka. Criação de conhecimento na empresa: como as empresas japonesas geram a dinâmica da inovação. Rio de Janeiro: Campus, 1997.

NUSSENZVEIG, H. Moysés. Complexidade e caos. Rio de Janeiro: UFRJ, COPEA, 1999.

SINGER, Paul. Introdução à economia solidária. São Paulo: Editora Fundação Perseu Abramo, 2002. 